\title{
Functional role of estrogen in pituitary tumor pathogenesis
}

\author{
Anthony P. Heaney, Manory Fernando, and Shlomo Melmed \\ Cedars-Sinai Research Institute, University of California Los Angeles School of Medicine, Los Angeles, California, USA \\ Address correspondence to: Shlomo Melmed, Cedars-Sinai Medical Center, \\ 8700 Beverly Boulevard, Room 2015, Los Angeles, California 90048, USA. \\ Phone: (310) 423-4691; Fax: (310) 423-0119; E-mail: Melmed@csmc.edu.
}

Received for publication September 21, 2001, and accepted in revised form December 10, 2001.

\begin{abstract}
Pituitary hyperplasia and lactotroph replication are induced by estrogen. The product of the pituitary tumor transforming gene $(P T T G)$ exhibits in vitro and in vivo transforming activity and induces basic bFGF secretion, thereby modulating pituitary angiogenesis and tumor formation. We demonstrated previously that pituitary pttg is induced by estrogen and bFGF, the latter being expressed in a concordant fashion with pttg in experimental and human pituitary adenomas. We now elucidate the role of estrogen in paracrine regulation of pituitary tumorigenesis by PTTG. Coincident with the circulating rat estradiol surge and maximal pituitary proliferation, pituitary pttg mRNA, bFGF, and VEGF expression increased approximately threefold during proestrus and estrus. Osmotic mini-pump coinfusion of estrogen and antiestrogen abrogated estrogen-induced pituitary pttg expression in vivo, suppressed serum PRL concentrations by $88 \%$, and attenuated prolactinsecreting pituitary tumor growth by $41 \%$ in rats. Antiestrogen treatment of primary human pituitary tumor cultures reduced PTTG expression approximately $65 \%$. Pituitary pttg, bFGF, and VEGF are cyclically expressed during the rat estrus cycle, concordantly with estrogen levels. Because antiestrogens reduced PTTG expression in human pituitary tumors in vitro and suppressed experimental tumor growth in vivo, concomitantly with reduced PRL secretion, these results indicate a role for selective antiestrogens in treating pituitary tumors.
\end{abstract}

J. Clin. Invest. 109:277-283 (2002). DOI:10.1172/JCI200214264.

\section{Introduction}

Pituitary tumor transforming gene (PTTG), originally isolated from $\mathrm{GH} 4$ pituitary cells, is tumorigenic in vivo $(1,2)$ and is the mammalian homologue of a Xenopus securin inhibitor of chromatid separation (3). As a securin protein, PTTG is expressed in a cell-cycle dependent manner, peaking during the G2/M phase (4). Cells overexpressing PTTG exhibit increased bFGF secretion $(2,5)$, and conditioned medium derived from these stable transfectants induced in vitro and in vivo angiogenesis (6).

The human PTTG family consists of at least four homologous genes, of which $P T T G_{1}$ is located on chromosome 5q33 (7), and is expressed at low levels in several normal human tissues and abundantly expressed in neoplasms, including pituitary tumors, where highest expression was observed in prolactin-secreting (PRL-secreting) tumors (8-10). We recently demonstrated that pituitary pttg is regulated by estrogen and involved in early pituitary lactotroph transformation and onset of angiogenesis (11).

Because estrogens promote lactotroph proliferation, we elucidated the role of the estrogen receptor in paracrine regulation of pituitary tumorigenesis by PTTG. We show here that pituitary pttg, bFGF, and VEGF expression are regulated during the rat estrus cycle, with maximal expression occurring coincidentally with peak serum estradiol levels and proliferating cytoplasmic nuclear antigen (PCNA) expression. Furthermore, selective antiestrogen treatment blocks estrogen-induced pituitary pttg expression in vitro and in vivo and inhibits lactotroph tumor growth in vivo. Estrogen-regulated PTTG, bFGF, and VEGF expression may therefore play a role in the early molecular events leading to development of pituitary transformation and prolactinoma development.

\section{Methods}

Animals. Ovariectomized Fischer 344 rats (140-150 g; Harlan Sprague Dawley Inc., Indianapolis, Indiana, USA) were housed in a controlled environment (light on, $0500-1900$ hours, $24^{\circ} \mathrm{C}$ ) with free access to food and water, and their use was approved by the Institutional Animal Care and Use Committee. Subcutaneously implanted osmotic pumps (OP) (100 $\mu \mathrm{l}$, ALZET), containing 17- $\beta$-estradiol $(1,000 \mathrm{ng})$, 4-hydroxytamoxifen $(860 \mu \mathrm{g})$, ICI-182780 $(500 \mu \mathrm{g})$, or raloxifene $(480 \mu \mathrm{g})$ in $90 \%$ polyethylene glycol (PEG)/5\% ethanol/5\% DMSO solution were employed to infuse estrogen and/or antiestrogen for 48-hour intervals.

For study of pttg expression during the rat estrus cycle, daily vaginal smears were collected from twenty, 4-day cycling, virgin female Long-Evans rats (12 weeks of age), housed as above, to determine their estrus cycle patterns. Only animals that exhibited at least three consecutive 4day cycles were considered to be regularly cyclic and used in subsequent experiments. Rats were euthanized in the early afternoon (1400 hours) by $\mathrm{CO}_{2}$ inhalation, pituitary tissues immersed in liquid $\mathrm{N}_{2}$ and stored at $-80^{\circ} \mathrm{C}$ 
for RNA and/or protein extraction, and serum collected for estradiol and progesterone assay (12).

Rat pituitary GH3 cells in DMEM $(\sim 500,000)$ were inoculated subcutaneously in twenty 2 -month-old female Wistar-Furth rats. By 6 weeks, visible subcutaneous tumors developed, and animals were randomized to receive mini-OP infusion with vehicle $(90 \%$ PEG $/ 0.1 \%$ DMSO/9.9\% DMEM) or the pure antiestrogen ICI-182780 ( $0.5 \mu \mathrm{g}$ per day). Rats were euthanized by $\mathrm{CO}_{2}$ inhalation, and tumor volume calculated according to the formula, in centimeters: $(3.14 \times$ length $\times$ width $\times$ depth $) / 6$. Cell culture. $\mathrm{GH}_{3}$ rat pituitary (PRL- and growth hormone-secreting [PRL- and GH-secreting]) cells were cultured in Hams F12 medium supplemented with $15 \%$ horse serum (HS) and $2.5 \%$ FCS and antibiotics at $37^{\circ} \mathrm{C}$ in $5 \% \mathrm{CO}_{2}$. Subconfluent $\mathrm{GH} 3$ cells were maintained for 3 days in phenol red-free F12 with 15\% HS and $2.5 \%$ FCS, which had been pretreated with dextrancoated charcoal before treatment with diethylstilbestrol (DES; $10^{-8}$ and $\left.10^{-10} \mathrm{M}\right), 2-\mathrm{OH}$ estradiol $\left(10^{-6} \mathrm{M}\right)$, and/or ICI-182780 (Tocris Cookson Inc., Ballwin, Missouri, USA) $\left(10^{-6} \mathrm{M}\right)$. Serum estradiol assay confirmed significant removal of estrogens $(34 \mathrm{pg} / \mathrm{ml}$ pretreatment, $10 \mathrm{pg} / \mathrm{ml}$ after charcoal stripping).

Patients and tissues. Samples of 14 surgically resected invasive pituitary macroadenomas (six gonadotroph, five nonfunctioning, one GH-secreting, one PRL-secreting, and one ACTH-secreting) were obtained from 26 consecutive unselected patients after surgical resection, in accordance with institutional guidelines. For primary human pituitary cultures, pituitary tumor tissue, freshly obtained at surgery, was minced mechanically and digested for 45 minutes at $37^{\circ} \mathrm{C}$ with $0.35 \%$ collagenase and $0.1 \%$ hyaluronidase (Sigma Chemical Co., St. Louis, Missouri, USA) in $10 \mathrm{ml}$ DMEM. Cell suspensions were filtered and resuspended for 24 hours in low-glucose DMEM containing 10\% FBS, $2 \mathrm{mmol} / \mathrm{l}$ glutamine, and antibiotics, before treatment with vehicle or ICI-182780, $10^{-5}$ to $10^{-6} \mathrm{M}$, for 48 hours. Sufficient protein was obtained from eight cases (three gonadotroph, five nonfunctioning) for Western blot analysis.

Northern blot analysis. Total RNA was extracted from cell cultures and from excised tissues (after tissue homogenization) with TRIzol (Life Technologies Inc., Gathersburg, Maryland, USA). RNA derived from rat testes served as a positive control for PTTG expression. Electrophoresed RNA was transferred to Hybond-N nylon membranes (Amersham International, Amersham, United Kingdom), cross-linked, prehybridized (1 hour), and hybridized ( 2 hours) at $68^{\circ} \mathrm{C}$ with rat or human PTTG cDNA in the presence of $100 \mu \mathrm{g} / \mathrm{ml}$ salmon sperm DNA (Stratagene, La Jolla, California, USA). A 900-bp PTTG cDNA fragment spanning the entire coding region was labeled with $\left[\alpha^{-32} \mathrm{P}\right] \mathrm{dCTP}$ using Klenow enzyme (Life Technologies Inc.). Posthybridization washes were followed by air drying and autoradiography. PTTG $_{1}$ mRNA expression was quantitated using scanning densitometry and normalized to either $\beta$-actin or $18 \mathrm{~S}$ ribosomal RNA expression.
Western blot analysis. Proteins were prepared from pituitary tissues and cells using RIPA buffer $(100 \mathrm{mM} \mathrm{NaCl}$, $0.1 \%$ Triton $\mathrm{X}-100$, and $50 \mathrm{mM}$ Tris-HCL, $\mathrm{pH}$ 8.3) containing a cocktail of enzyme inhibitors ( $1 \mathrm{mM}$ phenylmethylsulfonylfluoride, $2 \mu \mathrm{g} / \mathrm{ml}$ aprotinin, and 200 $\mu \mathrm{g} / \mathrm{ml}$ leupeptin) and denatured $\left(2\right.$ minutes, $\left.100^{\circ} \mathrm{C}\right)$ in loading buffer. Protein concentration was determined by the Bradford assay using BSA as a standard. Soluble proteins $(50 \mu \mathrm{g})$ were separated by electrophoresis in $12 \%$ SDS-PAGE gels, transferred to PVDF membranes (Amersham International), incubated in 5\% non-fat milk in PBS-0.05\% Tween solution, followed by incubation with Ab's to bFGF $(1: 2,000), \operatorname{VEGF}(1: 2,000)$ (Santa Cruz Biotechnology Inc., Santa Cruz, California, USA), and PTTG (1: 5000), for 24 hours at $4^{\circ} \mathrm{C}$, or PCNA (Dako Corp., Carpinteria, California, USA) for 2 hours at room temperature. After washing in PBS- $0.05 \%$ Tween (six times for 10 minutes), blots were incubated with appropriate horseradish peroxidase-conjugated (HRP-conjugated) anti-IgGs for 1 hour at room temperature. After further washes, antigen-Ab complexes were visualized by the enhanced chemiluminescence (ECL) detection system on Hyperfilm ECL. PTTG expression was quantitated using scanning densitometry and normalized to $\beta$-actin expression

Statistical analysis. Results are expressed as mean plus or minus SEM values, and statistical analysis was performed using nonparametric $t$ test or ANOVA with Bonferroni's multiple comparison test, taking $P$ values less than 0.05 as significant.

\section{Results}

PTTG is regulated by estrogen in vivo. Because we had demonstrated previously that estrogen induces pttg mRNA in rat pituitary GH3 cells in vitro, we sought to determine the role of estrogen in pituitary pttg regulation in vivo. Coincident with the proestrus serum estradiol surge $(56 \pm 4 \mathrm{pg} / \mathrm{ml})$ in 4-day cycling virgin Long-Evans rats, pttg mRNA expression in pituitaryderived tissue extracts increased approximately sixfold during estrus (Figure 1). Because PTTG regulates bFGF expression (2), we examined pituitary bFGF and VEGF expression by Western blot analysis. Estrogenmediated increase in pituitary pttg mRNA expression during estrus was associated with an approximately 3.4-fold increase in pituitary bFGF and an approximately 2.2-fold increase in VEGF expression, respectively (Figure 2). Increased bFGF and VEGF was also evident in proestrus and preceded increased pituitary pttg mRNA expression by approximately 12 hours, suggesting that additional PTTG-independent estrogen-mediated mechanisms are also involved in bFGF and VEGF induction. PTTG exhibits cell-cycle dependent expression $(4,13)$, peaking during $\mathrm{G} 2 / \mathrm{M}$, and may be a marker of tumor invasiveness $(8,9)$. The relationship of pituitary proliferation and PTTG expression was therefore examined by testing pituitary PCNA expression. PCNA expression (Figure 2) peaked (approximately twofold) concordantly with maximal 


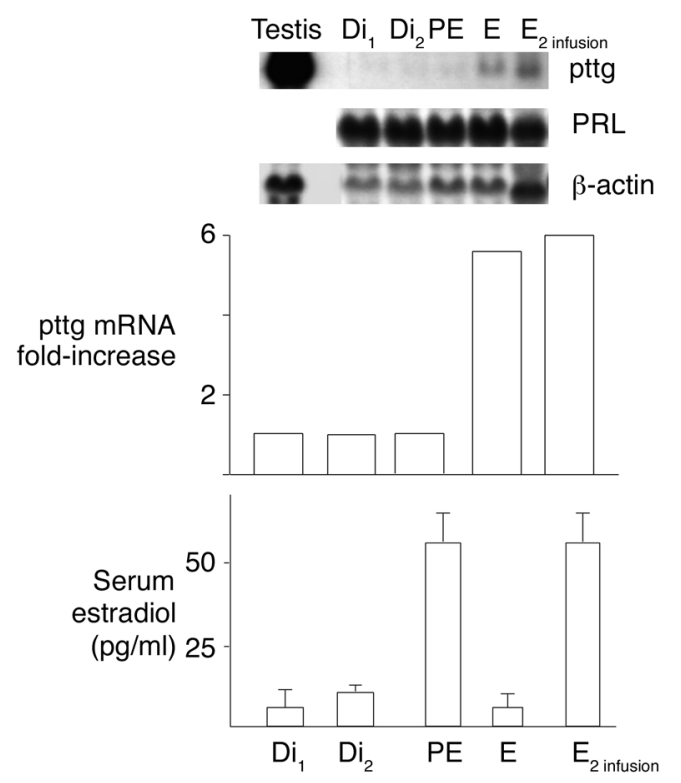

Figure 1

PTTG is regulated by estrogen in vivo. Representative Northern blot analysis and pttg mRNA quantitation of pituitary tissue extracts derived from twenty 4-day cycling virgin female Long-Evans rats and serum estradiol levels measured at 1400 hours. $\mathrm{Di}_{1}$, diestrus $1 ; \mathrm{Di}_{2}$, diestrus 2; PE, proestrus; $E$, estrus; $E_{2}$, estrogen-treatment. Rat testis served as a positive control. pttg, PRL, and $\beta$-actin (internal control). Each lane represents results of five pituitary glands.

PTTG expression, further indicating that cyclical PTTG expression during the rat estrus cycle is associated with estrogen-mediated pituitary proliferation.

Since naturally occurring catechol-metabolites of estradiol may mediate pituitary estrogenic actions (14, $15)$, we next examined the effects of $10^{-6} \mathrm{M} 2$-hydroxyestradiol $\left(2-\mathrm{OHE}_{2}\right)$ treatment on rat $\mathrm{GH} 3$ cells (Figure $3)$. Catecholestrogen treatment led to an approximately threefold increase in pituitary pttg mRNA expression $(P<0.01)$, similar to the magnitude of pttg mRNA induction following DES treatment $(P<0.01)$. Furthermore, both DES- and 2-OHE - mediated pttg mRNA induction were almost completely abrogated by coadministration of the specific antiestrogen, ICI-182780 $\left(10^{-5} \mathrm{M}, P<0.001\right)$, confirming that the catechol-estrogen effects on pituitary PTTG expression are mediated through the estrogen receptor.

In view of the observed in vivo increase in estrogenmediated pituitary PTTG expression and increased pituitary proliferation, we tested whether antiestrogen administration may block estrogen-mediated pituitary PTTG expression and PTTG-mediated pituitary actions. Mini-OP infusion of estrogen $(1 \mu \mathrm{g})$ for 48 hours resulted in an approximately 2.1 -fold increase in pituitary pttg mRNA expression. Coinfusion of estrogen $(1,000 \mathrm{ng})$ and one of these three antiestrogens, 4-hydroxytamoxifen $(860 \mu \mathrm{g})$, raloxifene $(480 \mu \mathrm{g})$, and ICI-182780 $(500 \mu \mathrm{g})$ for 48 hours (Figure 4$)$, or pretreatment of animals with progesterone $(2 \mathrm{mg})$ for 48 hours (data not shown), abrogated estrogen-induced pituitary pttg expression in vivo, supporting the rationale for use of antiestrogens as inhibitors of pituitary PTTG-mediated actions (Figure 4).

Selective antiestrogen treatment inbibits pituitary tumor growth in vivo. To examine the role of selective antiestrogens in inhibiting pituitary tumor growth, the pure estrogen receptor (ER) antagonist, ICI-182780 (0.5 $\mu \mathrm{g}$ per day), was then infused into Wistar-Furth rats harboring subcutaneous implanted PRL- and GH-secreting pituitary tumors. Six weeks after $\mathrm{GH} 3$ cell inoculation, all animals developed large tumors and were randomly assigned to receive vehicle or mini-OP infusion of ICI-182780 (0.5 $\mu \mathrm{g}$ per day). Before treatment, baseline serum PRL (vehicle, $365 \pm 26$; ICI, $345 \pm 76$ $\mu \mathrm{g} / \mu \mathrm{l}, P=\mathrm{NS}$ ), and tumor volume (vehicle, $372 \pm 38.3$; ICI, $329 \pm 79.7 \mathrm{~mm}^{3}, P=\mathrm{NS}$ ) were similar in animals receiving either mini-OP anti-estrogen infusion or vehicle (Figure 5). Tumor growth continued unabated in untreated animals, necessitating their euthanization due to tumor burden at 9 weeks. Administration of the pure ER antagonist, ICI-182780 (0.5 $\mu \mathrm{g}$ per day) suppressed serum PRL concentrations by $88 \%$ (vehicle, $25980 \pm 6603$; ICI, $3110 \pm 2091 \mathrm{ng} / \mathrm{ml}, P<0.001)$ and attenuated tumor growth by $41 \%$ (tumor volume: vehicle, $473 \pm 30$; ICI, $329 \pm 80 \mathrm{~mm}^{3}, P=0.03$ ) (Figure 5).
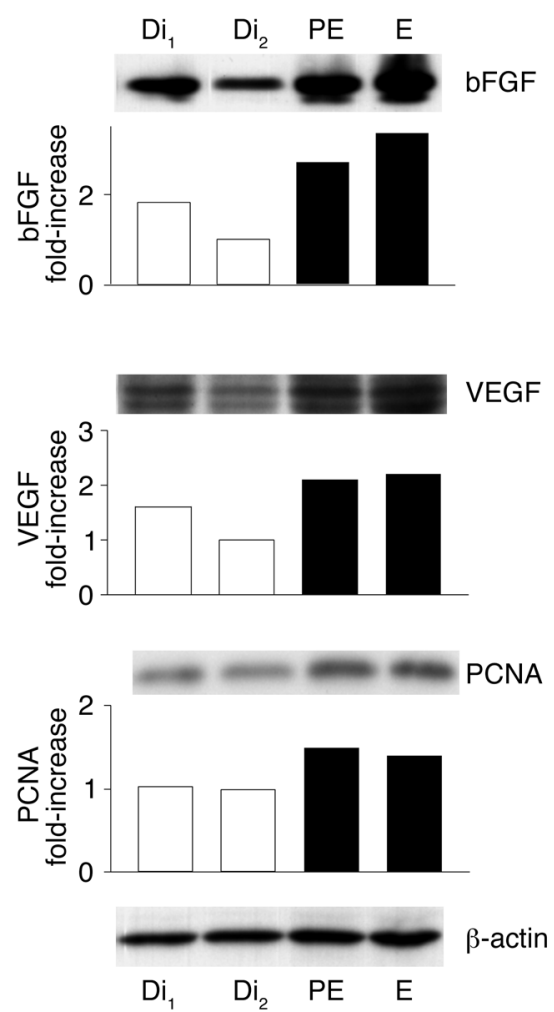

Figure 2

Cyclical pituitary bFGF and VEGF in rat estrus cycle. Western blot immunodetection and quantitation of bFGF, VEGF, PCNA, and $\beta$-actin (internal control) immunoreactivity in pituitary tissue extracts derived from 4-day cycling virgin female Long-Evans rats, sacrificed at 1400 hours. $\mathrm{Di}_{1}$, diestrus $1 ; \mathrm{Di}_{2}$, diestrus 2; PE, proestrus; $\mathrm{E}$, estrus. Each lane represents mean results of five pituitary glands. 

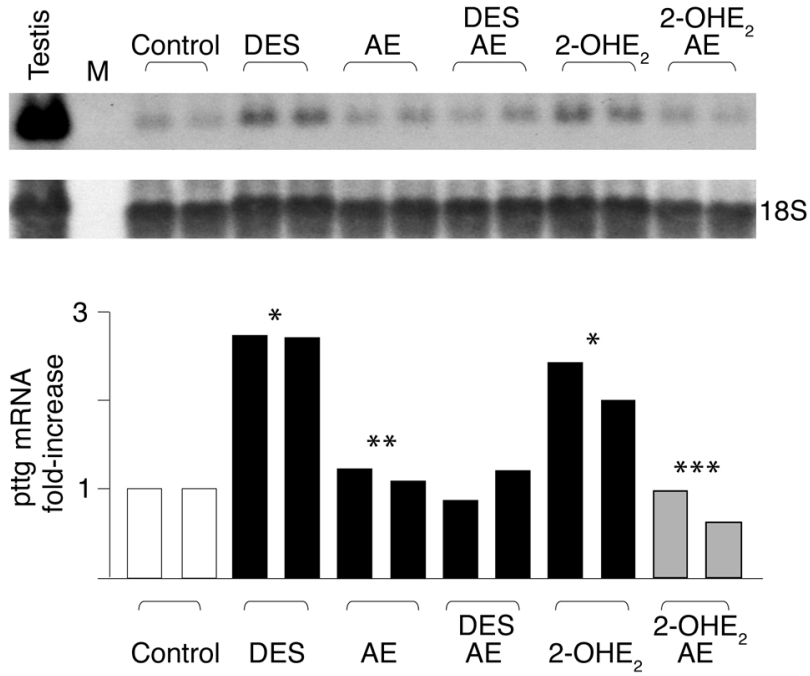

Figure 3

Regulation of pttg- and PRL-mRNA in vitro by DES and 2-OHE 2 . $\mathrm{GH} 3$ cells were incubated ( 3 days) in medium containing serum pretreated with charcoal-stripped serum before addition of DES $\left(10^{-8} \mathrm{M}\right)$ or $2-\mathrm{OHE}_{2}\left(10^{-6} \mathrm{M}\right)$ with/without the antiestrogen $\left(\mathrm{ICl}-18278010^{-6} \mathrm{M}\right)(\mathrm{AE})$ for 48 hours. pttg mRNA expression relative to $18 \mathrm{~S}$ (internal control) is depicted in lower panel. M, marker. Rat testis served as a positive control. Experiments were performed twice in triplicate wells for each data point. Each lane represents the mean of three dishes. ANOVA $=0.0003$. Bonferroni multiple comparisons: ${ }^{*} P<0.01$ compared with control; ${ }^{*} P<0.001$ compared with DES; and ${ }^{* *} P<0.001$ compared with $2-\mathrm{OHE}_{2}$.

Antiestrogens inhibit PTTG expression in primary pituitary tumor cultures in vitro. In view of our previous findings of enhanced PTTG mRNA and bFGF expression in human and animal pituitary tumor models, and because human pituitary tumors express ER (16), we treated primary pituitary tumor cultures from 14 consecutive surgically resected invasive pituitary macroadenomas (six gonadotroph, five nonfunctioning, one GH-secreting, one PRL-secreting, and one ACTH-secreting) with the antiestrogen ICI-182780 $\left(10^{-5}-10^{-6} \mathrm{M}\right.$ for 48 hours) in vitro (Figure 6) to examine antiestrogen effects on PTTG expression. Insufficient total RNA obtainable from human adenomas did not permit Northern blot analyses, but sufficient protein was obtained from eight tumors (three gonadotroph, five nonfunctioning) for Western blot analysis. ICI-182780 treatment of primary human pituitary tumor cultures reduced PTTG expression in four of these eight pituitary tumors (mean \pm SEM PTTG decrease, $64 \% \pm 9 \%$, range $20-100 \%$ ), further extending the findings in the animal tumor model. In three of these cases, decreased PTTG expression was associated with reduced PCNA expression (mean \pm SEM PCNA decrease, $47 \% \pm 9 \%$, range $34-74 \%$ ), in keeping with reduced proliferation rates. Decreased bFGF (mean \pm SEM bFGF decrease, $37 \% \pm 12 \%$, range $25-50 \%$ ) and Bcl-2 (mean \pm SEM Bcl-2 decrease, $49 \%$ \pm 16 , range $33-65 \%$ ) expression was observed in two of four antiestrogen-responsive tumors.

\section{Discussion}

Female rat pituitary cell proliferation fluctuates considerably, with highest activity occurring during estrus and lowest cell growth during diestrus (17). Doubleimmunostaining studies with 5-bromo-2'-deoxyuridine $(\mathrm{BrDU})$ and PCNA demonstrated that lactotrophs are the highest proportion of proliferating pituitary cells and that cell renewal rates double in the female compared with the male rat pituitary. Using a variety of proliferative assays, several studies have shown increased BrDU incorporation $(17,18)$, increased PCNA expression $(18)$ and increased polyamine synthesis (19) during the late proestrus and estrus phases of the rat estrus cycle. Estrus cycle-related pituitary proliferation is largely confined to lactotrophs (18), little BrDU incorporation is seen in other anterior pituitary cell types (20), and no significant changes in pituitary GH mRNA content occurs during the estrus cycle (21). We observed increased pituitary PCNA expression in association with increased pituitary PTTG mRNA, consistent with increased pituitary proliferative activity during the estrus phase. During proestrus, rising $17-\beta$-estradiol concentrations induce synchronous expression of ER, progesterone receptor (PR), and Ki-67 in estrogen-responsive tissues (22). In early diestrus, $17-\beta$-estradiol levels fall and progesterone levels plateau. Progesterone administration to rats before estrogen

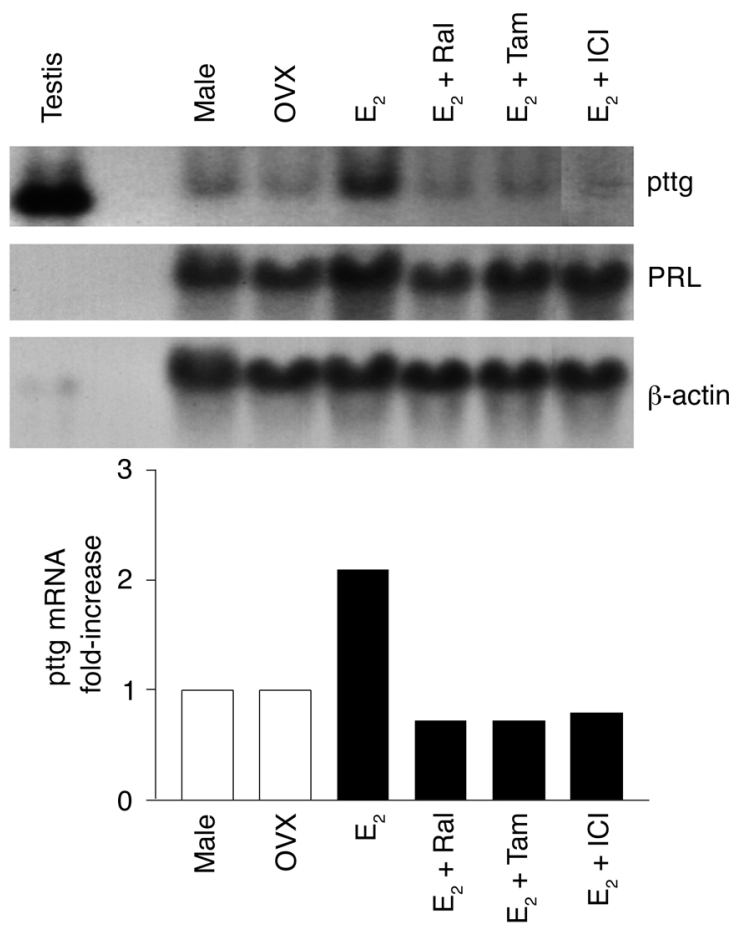

\section{Figure 4}

Estrogen-induced pituitary PTTG is abrogated by antiestrogens in vivo. Northern blot and quantitative analysis of pituitary tissue extracts derived following mini-OP $17-\beta$-estradiol infusion (1,000 ng for 48 hours) $\left(E_{2}\right)$, with/without coinfusion of the antiestrogens, raloxifene $(480 \mu \mathrm{g})(\mathrm{Ral})$; 4-hydroxytamoxifen $(860 \mu \mathrm{g})(\mathrm{Tam})$, or $\mathrm{ICl}-182780(500 \mu \mathrm{g})(\mathrm{ICl})$ for 48 hours in ovariectomised (OVX) F344 rats and vehicle-administered ovariectomized controls. $n=4$ animals in each group. pttg, PRL, and $\beta$-actin (internal control). 


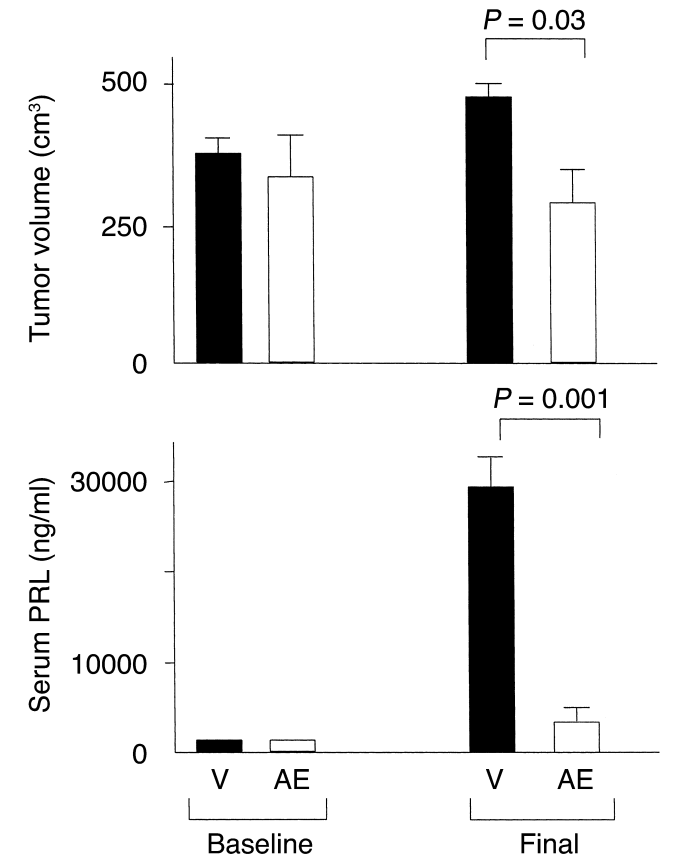

Figure 5

Selective antiestrogen treatment inhibits pituitary tumor growth in vivo. Pretreatment (baseline) and post-treatment tumor volumes and serum PR levels following mini-OP infusion of vehicle or antiestrogen $\mathrm{ICl}-182780$ ( $0.5 \mu \mathrm{g}$ per day) was infused in 20 female Wistar-Furth rats harboring subcutaneous pituitary tumors. All animals developed tumors. Each bar represents mean \pm SEM for ten animals per group. ${ }^{*} P=0.03 ;{ }^{*} P<0.001$.

administration blocked estrogen-mediated increases in pituitary pttg mRNA expression. A striking feature of the observed cyclical pituitary pttg mRNA expression is the rapidity of its induction and disappearance, being largely restricted to the estrus phase. Many hormones, growth factors, and cytokines are cyclically expressed during the estrus cycle and contribute to rapid pituitary cyclical lactotroph proliferative activity. Progesterone downregulates ER expression and may thereby limit estrogen-mediated pituitary pttg mRNA induction, providing a potential mechanism for the rapid decrease in pituitary pttg mRNA during diestrus (23).

In humans, combined exogenous estrogen/progestin administration in the form of oral contraceptives or postmenopausal hormone replacement therapy does not appear to initiate pituitary tumor development or to increase individual susceptibility to prolactinoma development $(24,25)$. Although not all authors agree, several lines of investigation support a role for estrogens in the development/progression of lactotroph tumors. In vitro estrogen administration stimulates PRL secretion (26, 27), PRL-secreting tumors are more common in females (28), and in vivo estrogen administration induces lactotroph tumors in humans and in animal models (29). Pituitary lactotroph hyperplasia occurs in physiological states of estrogen excess, during estrus in several species and in human pregnancy (18). Pituitary tumor growth occurs in approximately $23 \%$ of women harboring macro- prolactinomas during pregnancy, requiring surgery or reinstitution of dopamine agonist therapy (30). Furthermore, although pituitaries derived from men with prostate cancer treated with high-dose estrogen did not show increased lactotroph proliferation (31), several cases of lactotroph adenoma development have been reported in male-female transexuals given pharmacological doses of unopposed estrogen, emphasizing the powerful proliferative effects of unopposed estrogen on pituitary cells (32-34). Furthermore, ER expression is highest in PRLsecreting pituitary tumors derived from both male as well as female patients, as compared with other pituitary tumor types (35), and indeed may correlate with pituitary tumor size $(35,36)$. A role for estrogen in other pituitary tumor types is less clear, but the ER is expressed in all pituitary tumor subtypes $(15,35-39)$ and represents an attractive therapeutic target in pituitary tumors (40). In addition, although antiestrogen administration induces lactotroph apoptosis in vitro (41) and prevents lactotroph tumor development in in vivo animal models (42), previous studies have not examined the role of antiestrogens in inhibition or regression of pituitary tumor growth. ICI-182780, is a nonselective pure ER antagonist, which has potential advantages over tamoxifen-derivatives that have partial agonist actions in the pituitary (43). In addition, ICI-182780 appears to downregulate ER expression and block ER-mediated gene transcription (44). Tamoxifen has been administered to a patient with an aggressive nonfunctioning pituitary tumor, although it is unclear whether this tumor expressed ER (45).

We have demonstrated abundant and concordant PTTG and bFGF expression in human pituitary tumors (11). During early-stage lactotroph tumor development in a rat pituitary tumor model, we observed estrogenmediated increased pituitary pttg, bFGF, and VEGF expression, which was coincident with pituitary angiogenesis (11). We now show that pituitary pttg, bFGF, and VEGF are cyclically expressed during the rat estrus cycle, and that selective antiestrogen administration abrogates estrogen-stimulated pituitary pttg expression in vivo. Previous studies have demonstrated that tamoxifen administration prevents occurrence of subcutaneously inoculated pituitary tumors in animals (41).

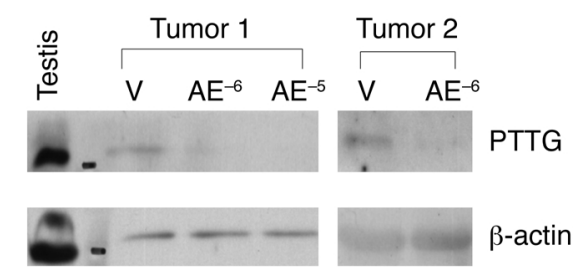

\section{Figure 6}

Antiestrogens inhibit PTTG expression in human pituitary tumor cultures in vitro. Representative Western blot immunodetection of PTTG in two primary pituitary gonadotroph (Luteinizing hormone immunopositive) tumor cultures following vehicle (V) or antiestrogen treatment $(A E)\left(\mathrm{ICl}-182780,10^{-6} \mathrm{M}\right.$ for 48 hours $)$. $\beta$-actin immunoblotting confirmed equivalent protein loading $(50 \mu \mathrm{g})$. Rat testes served as a positive control. 
However, because patients usually present with already established and actively growing pituitary tumors, the approach we have taken here, in commencing antiestrogen treatment in animals with already established pituitary tumors, more closely resembles the clinical therapeutic context. Administration of the pure antiestrogen, ICI-182780, suppressed experimental pituitary tumor growth in vivo ( $41 \%$ decrease) concomitant with reduced PRL secretion ( $~ 88 \%$ decrease), underpinning the powerful growth-inhibitory effect of ER blockade in lactotroph pituitary tumors. Furthermore, ICI-182780 reduced PTTG expression in human pituitary tumors in vitro, supporting a role for selective antiestrogen treatment in human pituitary tumors. This inhibitory effect was not confined to lactotroph tumors and was seen in various secretory and some nonfunctioning pituitary tumor subtypes, in keeping with previous studies identifying ER expression in all pituitary tumor subtypes (15, 35-39).

As in other tissues, multiple targets and complex interactions mediate estrogenic proliferative effects (46, $47)$ and include growth factor induction, direct cismediated actions on cell-cycle regulatory genes, and inhibition of apoptosis by induction of antiapoptotic proteins, such as Bcl-2 (48). We demonstrated previously concordant pituitary PTTG and bFGF induction in experimental animal and human pituitary tumors (11), and high Bcl-2 expression has been described in pituitary tumors (49). Therefore, we examined bFGF and $\mathrm{Bcl}-2$ expression in the ICI-responsive pituitary tumors. Decreased bFGF and Bcl-2 expression was observed in two of these four tumors, providing a potential mechanism for antiestrogen-mediated pituitary tumor growth inhibition.

Although high-dose estrogen administration to ovariectomised female rats leads to increased pituitary PTTG- and PRL-mRNA expression, we did not observe a concomitant change in pituitary PRL mRNA expression during the rat estrus cycle. One possible explanation for this is that pituitary PRL mRNA expression during the rat estrus cycle exhibits an episodic temporal expression pattern. The first peak is noted at approximately 1400 hours on proestrus day, the second at approximately 0400 hours on estrus, and the third at approximately 2200 hours on estrus (50). Because we euthanized animals at 1400 hours on the day of estrus, the rapid transitory peak in pituitary PRL mRNA expression may have been missed.

Catechol-estrogen formation by 2-hydroxylation is a major pathway of estrogen metabolism in the pituitary $(51,52) .2-\mathrm{OHE}_{2}$ combines dose-related estrogen agonistic and antagonistic properties, whereas $2-\mathrm{OHE}_{1}$ has predominantly antagonistic activities (14). 2- $\mathrm{OHE}_{2}$ treatment caused an approximately threefold increase in pituitary pttg mRNA. Estrogen 2-hydroxylase activity increases dramatically and specifically in rat brain during proestrus $(51,53,54)$, supporting our hypothesis that $2-\mathrm{OHE}_{2}$ mediates increased pituitary PTTG expression in the estrus cycle. Furthermore, our results, showing abrogation of $2-\mathrm{OHE}_{2}$-mediated PTTG induction with ICI-182780, support previous studies indicating that catechol-estrogen actions are mediated via the ER (15).

The regulation of pituitary PRL mRNA expression during the rat estrus cycle is complex and involves direct effects of estrogen and catechol metabolites, on PRL transcription, indirect activation of transcription followed by rapid and abundant PRL secretion, and mammotrope proliferation, respectively (50). Estrogen regulates pituitary PTTG mRNA expression, and we showed previously that PTTG overexpression leads to increased bFGF expression and that bFGF stimulates PTTG mRNA expression. bFGF treatment increases PRL transcription and secretion in vitro (55), and targeted bFGF overexpression induces lactotroph hyperplasia (56). These studies indicate that increased pituitary bFGF expression precedes increased pituitary PTTG mRNA expression, which in turn will lead to further increases in pituitary bFGF. It is possible that estrogen-mediated increases in PTTG and bFGF cooperatively serve to coordinate the complex temporal secretion of pituitary PRL.

The results show here that pituitary PTTG and bFGF are cyclically regulated by estrogen, peaking concomitantly with increased lactotroph proliferation during estrus. As a securin protein, PTTG expression alters during the normal cell-cycle, peaking at G2/M before mitosis. It is then rapidly degraded, because sustained PTTG expression dysregulates sister chromatid separation and results in cell aneuploidy (13). Failure to degrade PTTG in a timely manner may render pituitary cells susceptible to aneuploidy and subsequent transformation. We hypothesize that estrogen-mediated amplified and/or sustained pituitary PTTG expression, during normal physiological cyclical pituitary proliferation, predisposes the lactotroph to transformation and provides novel insight into factors promoting pituitary lactotroph tumor development.

The lack of adequate longer-term functional differentiated human pituitary tumor culture material makes comprehensive analysis in individual cases difficult, and much insight into pituitary tumor pathogenesis derives from in vitro and/or in vivo animal studies. It is not possible from this study to confirm that the ICI-182780-mediated tumor inhibition observed in animal models would occur in human pituitary tumors, but the observed decrease in human pituitary tumor PTTG expression by the antiestrogen supports the in vivo animal studies, showing antiestrogen-mediated inhibition of pituitary tumor proliferation. Therefore, given that most pituitary tumor subtypes express ER, the results support the use of selective antiestrogen management of pituitary tumors.

\section{Acknowledgments}

This work was supported by grants from NIH (CA-75979), Endocrine Fellows Foundation, The Annenberg Foundation, and The Doris Factor Molecular Endocrinology Laboratory. 
1. Pei, L., and Melmed, S. 1997. Isolation and characterization of a pituitary tumor-transforming gene (PTTG). Mol. Endocrinol. 11:433-441.

2. Zhang, X., et al. 1999. Structure, expression and function of human pituitary transforming gene (PTTG). Mol. Endocrinol. 13:156-166.

3. Zou, H., McGarry, T.J., Bernal, T., and Kirschner, M.W. 1999. Identification of a vertebrate sister-chromatid separation inhibitor involved in transformation and tumorigenesis. Science. 285:418-422.

4. Yu, R., Ren, S.-G., Horwitz, G.A., Wang, Z., and Melmed, S. 2000. Pituitary tumor transforming gene (PTTG) regulates placental JEG-3 cell division and survival: evidence from live cell imaging. Mol. Endocrinol. 14:1137-1146.

5. Heaney, A.P., Nelson, V., Fernando, M., and Horwitz, G.A. 2001. Early transforming events in thyroid tumorigenesis and their association with follicular lesions. J. Clin. Endocrinol. Metab. 86:5025-5032.

6. Ishikawa, H., Heaney, A.P., Yu, R., Horwitz, G.A., and Melmed, S. 2001. Human pituitary tumor transforming gene (PTTG) induces angiogenesis and correlates with tumor vascularity. J. Clin. Endocrinol. Metab. 86:867-874

7. Prezant, T.P., Kadioglu, P., and Melmed, S. 1999. An intronless homolog of human proto-oncogene $h P T T G$ is expressed in pituitary tumors: evidence for $h P T T G$ family. J. Clin. Endocrinol. Metab. 84:1149-1152.

8. Heaney, A.P., et al. 2000. Pituitary tumor transforming gene: a novel marker in colorectal tumors. Lancet. 355:716-719.

9. Zhang, X., et al. 1999. Pituitary tumor transforming gene expression in human pituitary adenomas. J. Clin. Endocrinol. Metab. 84:761-767.

10. Chen, L.L., Puri, R., Lefkowitz, E.J., and Kakar, S.S. 2000. Identification of the human pituitary tumor transforming gene (hPTTG) family: molecular structure, expression and chromosomal localization. Gene. 248:41-50.

11. Heaney, A.P., Horwitz, G.A., Wang, Z., Singson, R., and Melmed, S. 1999. Early involvement of estrogen-induced pituitary tumor transforming gene $\left(P T T G_{1}\right)$ and fibroblast growth factor (bFGF) expression in prolactinoma pathogenesis. Nat. Med. 5:1317-1321.

12. Lu, J.K.H., LaPolt, P.S., Nass, T.E., Mah, D.N., and Judd, H.L. 1985. Relation of circulating estradiol and progesterone to gonadotrophin secretion and estrous cyclicity in aging rats. Endocrinology. 116:1953-1959.

13. Yu, R., Heaney, A.P., Wenge, L., Jiandong, and C., Melmed, S. 2000. Pituitary tumor transforming gene (PTTG) causes aneuploidy and p53dependent and $\mathrm{p}-53$ independent apoptosis. J. Biol. Chem. 275:36502-36505.

14. Paul, S.M., and Axelrod, J. 1977. Catechol estrogens: presence in brain and endocrine tissues. Science. 197:657-659.

15. Lamberts, S.W.J., Verleun, T., and Oosterom, R. 1985. Studies on the effects of catecholestrogens on prolactin secretion by cultured normal rat anterior pituitary cells. Endocrinology. 116:2631-2636.

16. Stefeananu, L., et al. 1994. In situ hybridisation study of estrogen receptor messenger ribonucleic acid in human adenohypophyseal cells and pituitary adenomas. J. Clin. Endocrinol. Metab. 78:83-88.

17. Oishi, Y., Okuda, M., Takahashi, H., Fujii, T., and Morii, S. 1993. Cellular proliferation in the anterior pituitary gland of normal adult rats: influence of sex, estrous cycle, and circadian change. Anat. Rec. 235:111-120.

18. Yin, P., Arita, J. 2000. Differential regulation of prolactin release and lactotrope proliferation during pregnancy, lactation and the estrous cycle. Neuroendocrinology. 72:72-79.

19. Persson, L., Nilsson, M., and Rosengren, E. 1985. Ornithine decarboxylase activity and polyamines in the anterior pituitary gland during the rat estrus cycle. J. Endocrinol. 107:83-87.

20. Hashi, A., Mazawa, S., Kato, J., and Arita, J. 1995. Pentobarbital anesthesia during the proestrus afternoon blocks lactotroph prolifearation occurring on estrus in female rats. Endocrinology. 136:4665-4671.

21. Suganuma, N., Kikkawa, F., Seo, H., Matsui, N., and Tomoda, Y. 1993. Poly (adenosine diphosphate-ribose) synthesis in the anterior pituitary of the female rat throughout the estrous cycle: study of possible relation to cell proliferation and prolactin gene expression. J. Endocrinol. Invest. 16:475-480

22. Aupperele, H., et al. 2000. Cyclical endometrial steroid hormone receptor expression and proliferation intensity in the mare. Equine. Vet. J. 32:228-232.

23. Piroli, C., Grillo, C.A., Ferrini, M.G., Lux-Lartos, V., and De Nicola, A.F. 1996. Antagonism by progesterone of diethylstilbestrol-induced pituitary tumorigenesis in Fischer 344 rats: effects of sex steroid receptor and tyrosine hydroxylase mRNA. Neuroendocrinology. 63:530-539.

24. Molitch, M.E. 2001. Prolactinomas. In Prolactin. N.D. Horseman, editor. Kluwer Academic Publishers. Boston, Massachusetts, USA. 82-99.

25. Wingrave, S.J., Kay, C.R., and Vessey, M.P. 1980. Oral contraceptives and pituitary adenomas. Br. Med.J. 1:685-686.

26. Lieberman, M.E., Maurer, R.A., and Gorski, J. 1978. Estrogen control of prolactin synthesis in vitro. Proc. Natl. Acad. Sci. USA. 75:5946-5949.

27. Maurer, R.A. 1982. Estrogen regulates the transcription of the prolactin gene. J. Biol. Chem. 257:2133-2136.

28. Schlecthe, J.A. 1997. Prolactinoma. Curr. Ther. Endocrinol. Metab. 6:45-47.
29. Gorski, J., Wendell, D., and Chun, T.-Y. 1997. Estrogens and the genetic control of tumor growth. Prog. Clin. Biol. Res. 396:233-243.

30. Molitch, M.E. 1999. Management of prolactinomas during pregnancy. J. Reprod. Med. 44(Suppl.):1121-1126.

31. Scheithauer, B.W., Kovacs, K.T., Randall, R.V., and Ryan, N. 1989. Effects of estrogen on the human pituitary: a clinicopathologic study. Mayo Clin. Proc. 64:1077-1084.

32. Gooren, L.J., Assies, J., Asscheman, H., de Slegte, R., and van Kessel, H. 1988. Estrogen-induced prolactinoma in a man. J. Clin. Endocrinol. Metab. 66:444-446.

33. Kovacs, K., Stefeaneau, L., Ezzat, S., and Smyth, H.S. 1994. Prolactin-producing pituitary adenoma in a male-to-female transsexual patient with protracted estrogen administration. A morphologic study. Arch. Pathol. Lab. Med. 118:562-565.

34. Serri, O., Noiseux, D., Robert, F., and Hardy, J. 1996. Lactotroph hyperplasia in an estrogen treated male-to-female transsexual patient. J. Clin. Endocrinol. Metab. 81:3177-3179.

35. Jaffrain-Rea, M.L., et al. 1996. Cellular receptors for sex steroids in human pituitary adenomas. J. Endocrinol. 15:175-184.

36. Nakao, H., et al. 1989. Enzyme immunoassay for estrogen receptor in human pituitary adenomas. Acta Endocrinol. 120:233-238.

37. Scully, K.M., et al. 1997. Role of estrogen receptor- $\alpha$ in the anterior pituitary gland. Mol. Endocrinol. 11:674-681.

38. Zafar, M., et al. 1995. Cell-specific expression of estrogen receptor in the human pituitary and its adenomas. J. Clin. Endocrinol. Metab. 80:3621-3627.

39. Chaidrun, S.S., Swearingen, B., and Alexander, J.M. 1998. Differential expression of estrogen receptor-beta (ER-beta) in human pituitary tumors: functional interactions with ER alpha and a tumor-specific splice variant. J. Clin. Endocrinol. Metab. 83:3308-3315.

40. Lee, E.J., Duan, W.R., Jakacka, M., Gehm, B.D., and Jameson, J.L. 2001 Dominant negative ER induces apoptosis in $\mathrm{GH}(4)$ pituitary lactotrope cells and inhibits tumor growth in nude mice. Endocrinology. 142:3756-3763.

41. Newton, C.J. 1995. Estrogen receptor blockade by the pure antiestrogen, ZM 182780, induces death of pituitary tumor cells. J. Steroid. Biochem. Mol. Biol. 55:327-336.

42. de Quijada, M., Timmermans, H.A., and Lamberts, S.W. 1980. Tamoxifen suppresses both the growth of prolactin-secreting pituitary tumors and normal prolactin synthesis in the rat. J. Endocrinol. 86:109-116.

43. Wakeling, A., Dukes, M., and Bowler, J. 1991. A potent specific pure antiestrogen with clinical potential. Cancer. Res. 51:3867-3873.

44. Coopman, P., et al. 1994. Anti-proliferative and anti-estrogenic effects of ICI 164,384 and ICI 182,780 in 4-OH-tamoxifen-resistant human breast cancer cells. Int. J. Cancer. 56:295-300.

45. Lamberts, S.W., de Quijada, M., and Kkijn, J.G. 1980. The effect of tamoxifen on GH and PRL secretion by human pituitary tumors. $J$. Endocrinol. Invest. 3:343-347.

46. Hall, J.M., Couse, J.F., and Korach, K.S. 2001. The multifaceted mechanisms of estradiol and estrogen receptor signaling. J. Biol. Chem. 276:36869-36872.

47. Feldman, M., Ruan, W., Tappin, I., Wieczorek, R., and Kleinberg, D.L. 1999. The effect of GH on estrogen receptor expression in the rat mammary gland. J. Endocrinol. 163:515-522.

48. Perillo, B., Sasso, A., Abbondanza, C., and Palumbo, G. 2000. 17 betaestradiol inhibits apoptosis in MCF-7 cells, inducing bcl-2 expression via two estrogen-responsive elements present in the coding sequence. Mol. Cell. Biol. 20:2890-2901.

49. Wang, D.-G., et al. 1996. Expression of Bcl-2 oncoprotein in human pituitary tumours: comparison with c-Myc. J. Clin. Pathol. 49:795-797.

50. Shimokawa, N., Kato, Y., Imai, K., and Wakabayashi, K. 1990. Changes in content of prolactin mRNA during the rat estrus cycle. Exp. Clin. Endocrinol. 96:8-14.

51. Fishman, J., Norton, B., and Krey, L. 1980. Hydroxylation of estrogens in the brain participates in the initiation of the provulatory $\mathrm{LH}$ surge in the rat. Biochem. Biophys. Res. Commun. 93:471-477.

52. Ball, P., Knuppen, R. 1978. Formation of 2- and 4-hydroxyestrogens by brain, pituitary, and liver of the human fetus. J. Clin. Endocrinol. Metab. 47:732-737.

53. Cecchini, D.J., et al. 1983. Radioimmunoassay of 2-hydroxyestrone in plasma during the estrous cycle of the rat: interrelationships with estradiol, progesterone, and the gonadotrophins. Endocrinology. 112:1122-1126.

54. Panda, S.K., and Chattoraj, S.C. 2001. Urinary excretion of catecholestrogens in preovulatory LH surge during the 4-day estrus cycle of rats. J. Endocrinol. Invest. 24:334-339.

55. Baird, A., et al. 1985. A nonmitogenic pituitary function of fibroblast growth factor: regulation of thyrotrophin and prolactin secretion. Proc. Natl. Acad. Sci. USA. 82:5545-5549.

56.Weiner, R.I., Windle, J., Mellon, P., and Schechter, J. 1991. Role of FGF in tumorigenesis of the anterior pituitary. J. Endocrinol. Invest 14(Suppl.):10. (Abstr.) 